\title{
Evidence that photos promote rosiness for claims about the future
}

\author{
Eryn J. Newman ${ }^{1,2} \cdot$ Tanjeem Azad $^{3} \cdot$ D. Stephen Lindsay ${ }^{3} \cdot$ Maryanne Garry $^{1}$
}

Published online: 19 September 2016

(C) Psychonomic Society, Inc. 2016

\begin{abstract}
When people rapidly judge the truth of claims about the present or the past, a related but nonprobative photo can produce "truthiness," an increase in the perceived truth of those claims (Newman, Garry, Bernstein, Kantner, \& Lindsay, 2012). What we do not know is the extent to which nonprobative photos cause truthiness for the future. We addressed this issue in four experiments. In each experiment, people judged the truth of claims that the price of certain commodities (such as manganese) would increase (or decrease). Half of the time, subjects saw a photo of the commodity paired with the claim. Experiments $1 \mathrm{~A}$ and $1 \mathrm{~B}$ produced a "rosiness" bias: Photos led people to believe positive claims about the future but had very little effect on people's belief in negative claims. In Experiment 2, rosiness occurred for both close and distant future claims. In Experiments $3 \mathrm{~A}$ and $3 \mathrm{~B}$, we tested whether rosiness was tied to the perceived positivity of a claim. Finally, in Experiments $4 \mathrm{~A}$ and $4 \mathrm{~B}$, we tested the rosiness hypothesis and found that rosiness was unique to claims about the future: When people made the same judgments about the past, photos produced the usual truthiness pattern for both positive and negative claims. Considered all together, our data fit with the idea that photos may operate as
\end{abstract}

Eryn J. Newman

erynnewm@usc.edu

1 Victoria University of Wellington, Wellington, New Zealand

2 Mind and Society Center, Department of Psychology, University of Southern California, Los Angeles, CA 90089-1061, USA

3 University of Victoria, Victoria, British Columbia, Canada hypothesis-confirming evidence for people's tendency to anticipate rosy future outcomes.

Keywords Truthiness $\cdot$ Photographs $\cdot$ Fluency $\cdot$ Future thinking

People's predictions about the future are colored by cognitive biases. In the face of uncertainty, we often ignore base rates, overvalue resemblances, and overrely on our emotions. Perhaps the best known of these pervasive biases hinges on cognitive availability: Future scenarios seem more likely if, for example, they are easy to imagine (Jacoby, Kelley, \& Dywan, 1989; Tversky \& Kahneman, 1974; see also Alter \& Oppenheimer, 2009, for the similar notion of "retrieval fluency"). The contents of the imagined scenario are likely nonprobative: They probably do not reliably reveal the likelihood that the scenario will actually occur. But people do sometimes use the ease with which they can imagine or think about a scenario as a gauge to its likelihood (Szpunar \& Schacter, 2013; see also Unkelbach, 2006, 2007). In one study, people tended to think they were more likely to contract a disease with easy-to-imagine symptoms (headache or low energy) than one with difficult-to-imagine symptoms (inflamed liver or a malfunctioning nervous system; Sherman, Cialdini, Schwartzman, \& Reynolds, 1985). In another study, people on average expressed more interest in visiting travel destinations that were easier to imagine (Petrova \& Cialdini, 2005). When people can easily imagine nonprobative information about the future, they often mistakenly construe that information and the ease of simulating that future event as probative. And so, manipulations that help people imagine a future scenario more easily should make that future seem more likely. Photographs are especially powerful tools that help people imagine. To what extent can 
photographs make future scenarios seem true? That is the question we addressed here.

\section{Photographs promote ease of imagination}

We know that photographs - even nonprobative ones, which do not provide any evidence that an event has happened - can lead people to falsely remember their past. In one study, subjects heard three descriptions of childhood events, two true and one false (Lindsay, Hagen, Read, Wade, \& Garry, 2004). The false description was about the subject and a friend sneaking Slime - the gooey, sticky children's toy — into their grade school teacher's desk and later getting in trouble. The subjects' task was to recall as much as possible about each event. Over a week, one group received a verbal suggestions, but another group received the suggestions plus a copy of that school-year's class photo (supplied to the researchers by the subjects' parents). By the end of the week, $45 \%$ of the "suggestion" people reported something about the Slime episode, as compared with $78 \%$ of the "suggestion plus photo" people. Moreover, two-thirds of those who also saw the photo were judged by raters to have reported false memories that were marked by high confidence (see Blandón-Gitlin, Pezdek, Lindsay, \& Hagen, 2009, for a content analysis of true and suggested events).

We can consider these findings in the language of the source-monitoring framework (Johnson, Hashtroudi, \& Lindsay, 1993; Lindsay, 2008, 2014). Source monitoring helps us understand how people decide whether a particular mental event really happened, and from what source it came: Is it something one simply imagined, or something one really experienced? When mental products such as thoughts, images, and feelings come to mind easily, are full of sensory detail - such as vivid, concrete images - and leave little record of cognitive operations that might otherwise point to an internal origin, people typically attribute those mental products to real experience. The results from Lindsay and colleagues' (2004) findings fit with the idea that the nonprobative class photo made it easier for subjects to generate thoughts and images about themselves, their friends, their teacher, and the event itself. Coupled with a bias to seek confirming information (Nickerson, 1998) and a gradual loss of source memory over the week-long procedure (see Lindsay, 2008), subjects may have construed these mental products as evidence that the suggested event really happened.

We also know from recent work that nonprobative photos can more rapidly nudge people to find associated claims true (Fenn, Newman, Pezdek, \& Garry, 2013; Newman, Garry, Bernstein, Kantner, \& Lindsay, 2012). In this paradigm, people quickly judge a series of trivia claims (The liquid metal inside a thermometer is magnesium) as true or false. Sometimes the claims appear with a nonprobative photo (such as a thermometer), but other times the claims appear alone. The general finding is that when people make rapid judgments about the truth of a claim, nonprobative but relevant photos nudge them toward believing that claim - an effect known as "truthiness." This "truthiness" research, too, fits with the idea that nonprobative photos help people generate thoughts and images related to a claim. In turn, a bias to confirm a claim may encourage people to construe these mental products and the ease of generating them as evidence that the claim is true (Newman et al., 2012; Newman et al., 2015). Truthiness research also suggests that nonprobative photos bias judgments about the past and present by what seem to be similar processes-processes like those we know cause future scenarios to seem true.

To investigate the degree to which nonprobative photographs produce truthiness for future scenarios, we asked the people in our present experiments to make judgments about each of a large set of commodities, such as gabardine, benzene, and thyme. For each commodity, one group quickly responded "true" or "false" to the scenario "This commodity is likely to have increased in price three months from today." To address the possible counterexplanation that people might think that commodities with photos are more valuable, and thus would increase in price, we asked another group to respond to the scenario "This commodity is likely to have decreased in price three months from today." In both conditions, half of the scenarios appeared with a photo of the commodity.

On the basis of our review of the memory and future judgments literatures, we might expect that nonprobative photos would produce truthiness for the future. Indeed, the sourcemonitoring framework accommodates the idea that people use similar approaches when judging past and present outcomes to decide the likelihood that a particular future event will really happen. That is, when thoughts, images, and feelings about future events come to mind easily, are full of sensory details, and are low on markers of cognitive operations, people typically decide that the future event is more likely to really happen (see Johnson \& Sherman, 1990, and Schacter, Addis, \& Buckner, 2007, for related views). Thus, we might expect that nonprobative photos would operate in similar ways for judgments about the past, present, and future, making related thoughts, feelings, and images spring to mind easily and serving as evidence for claims regardless of the direction of time. On the other hand, we might expect that photos would not influence people's judgments about the future. After all, photos record the past, not the future. Although it makes sense that people may gather evidence from a photo to make judgments about a past event, it makes much less sense to gather evidence from a photo to make judgments about a future event.

Below we report how we determined our sample sizes, all data exclusions, all manipulations, and all measures used in our experiments. Decisions about sample size and measures 
were made prior to the data analysis. The data (both the initial raw data and the more processed data files) from the studies reported here are posted on the first author's ResearchGate profile, as are copies of the materials and of the programs used to present them.

\section{Experiment 1A and 1B}

\section{Method}

Subjects In Experiment 1A, 81 students from Victoria University of Wellington participated in the study for course credit. In Experiment 1B, 76 students from the University of Victoria participated in the study for optional bonus points. If the effect sizes of photos are comparable for past and future judgments, then on the basis of our prior research, the effects should have similar precisions when $N \mathrm{~s}$ were in the mid $70 \mathrm{~s}$, so that is what we set out to test; the final $N$ s varied depending on no-show rates (Newman et al., 2012).

Design We used a 2 (Photo: yes, no) $\times 2$ (Claim: increase, decrease) mixed design, manipulating the presence of a photo within subjects.

Materials and procedure We told subjects that they would see a series of commodities ("raw materials or goods that have some value and are often used to make other products"). Their task was to decide, for each commodity, whether the claim "This commodity is likely to have increased in price three months from today" was true or false. Half of the subjects made the same decision for the claim "This commodity is likely to have decreased in price three months from today." To reduce a potential tendency to assume that prices typically increase over time, we told subjects that commodity prices often increase and decrease week to week and month to month.

Subjects saw 30 commodities, presented one at a time using the Superlab software. We developed this list by selecting nouns from the MRC Psycholinguistic word database (http://websites.psychology.uwa.edu. au/school/MRCDatabase/uwa mrc.htm) that, given our broad definition, are plausible commodities. We selected nouns that fell at the lower end of the familiarity scale and the upper end of the imagery scale (see the supplementary materials for our list of nouns), so although the nouns were unfamiliar, they were relatively easy to picture if you knew what they were, and were easily represented in a photo (familiarity: $M=343.37, S D=71.01$, range $=199-442$; imagery: $M=492.57, S D=72.62$, range $=402-627$; database range $=100-700$ ).

We told subjects that sometimes they would see a photo with the commodity and sometimes they would not, and we showed them gold as an example in both the photo and nophoto versions. The photos always depicted the commodity, and all of the photos used in the experiments reported here can be found on the first author's ResearchGate profile. We did not provide any instructions about how subjects should use the photos; instead, we said "don't try to analyze and puzzle things out, just go with your gut feel or hunch," and that they should decide the truth of the claim as quickly as possible, within a couple of seconds. The names of the commodities appeared one at a time, in large black font against a white background. Half of these names appeared with a photo depicting the commodity (see Fig. 1). The order of commodities was randomized anew for each subject and counterbalanced so that each commodity appeared equally often with and without a photo.

In Experiment 1B we replicated Experiment 1A, except that we increased the number of commodities to 68 and broadened the range of familiarity and imagery (familiarity: $M=$ $330.79, S D=127.79$, range $=103-518$; imagery: $M=430.49$, $S D=145.79$, range $=162-649 ;$ database range $=100-700)$.

\section{Results and discussion}

Our primary aim was to determine the extent to which nonprobative photographs can make future scenarios seem true. To answer this question, we calculated the proportion of times each subject said claims were true, grouped those responses according to whether those scenarios had appeared with or without a nonprobative photo; the results are displayed in Fig. 2. The black bars show the responses to commodities that appeared with photos; the gray bars show the responses when commodities appeared alone. In addition, the left bars show the pattern of responses for the scenario in which commodities would increase in price, and the right bars show the pattern for the scenario in which commodities would decrease in price.

As the figure shows, nonprobative photos produced truthiness for the future. That is, relative to the no-photo condition, subjects responded "true" more often to future scenarios that appeared with a photo, $F(1,79)=4.61, p=.03$, mean difference $=.05$ (i.e., a $5 \%$ raw effect size), $95 \%$ confidence interval (CI) $[.004, .09]$. The photo effect in Experiment 1A was small (and the lower bound of the CI very close to 0 ), so it is reassuring that a photo effect was also obtained in Experiment $1 \mathrm{~B}, F(1,74)=16.23, p<.01$, mean difference $=$ $.07,95 \%$ CI $[.03, .10]$. In Experiment $1 \mathrm{~B}$, we also found a marginal tendency toward a main effect of claim, suggesting that people more often agreed with the "increase" claim than with the "decrease" claim, $F(1,74)=4.03, p=.05$, mean difference $=.06,95 \% \mathrm{CI}[.004, .12]$. This trend suggests a bias toward assuming that prices tend to increase. No significant Photo $\times$ Claim interaction emerged in either Experiment $1 \mathrm{~A}$ or $1 \mathrm{~B}$, both $F \mathrm{~s}<1.32$, but the pattern suggests that photos 


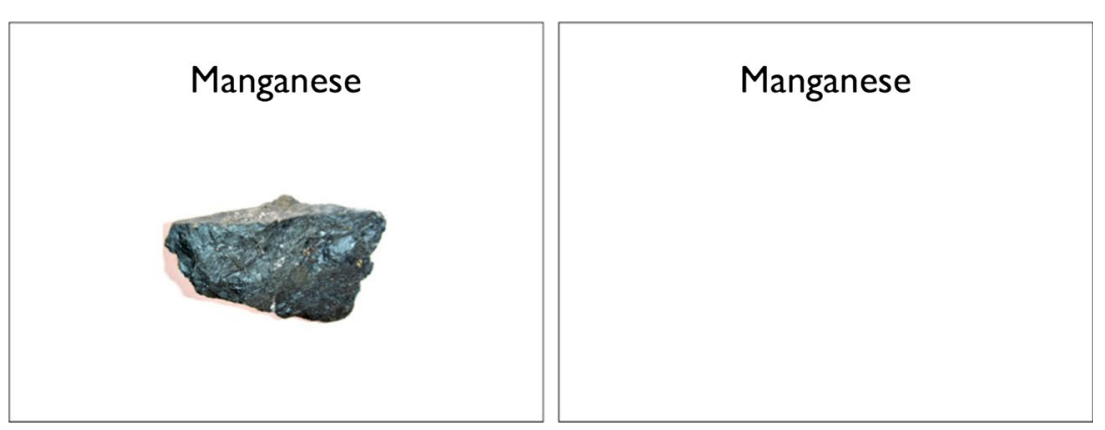

Fig. 1 Example of commodity names appearing either with or without a photo. Photo credit: http://notanminerals.com/Pr-Manganese.html\#sthash. ozPLylof.dpuf

exerted more of an influence on the "increase" than on the "decrease" claim (a pattern that we replicated in subsequent experiments). Taken together, our findings fit with recent research showing that nonprobative photos can promote the truthiness of associated claims (Fenn et al., 2013; Newman et al., 2012; Newman et al., 2015)

Did subjects have any insight into the way that photos biased them? When we asked subjects at the end of Experiment $1 \mathrm{~A}$ how the photographs influenced their decisions, ${ }^{1} 52 \%$ of the people said the photographs helped them understand what the commodity was, $10 \%$ told us that the photo helped them imagine the commodity, and only $10 \%$ reported that the photo added credibility to the claim (another $28 \%$ said that the photo did nothing or gave a different explanation, such as that the photo made them respond more slowly). Thus, the majority of subjects reported that the photos boosted their understanding or helped them picture the commodity - a belief that fits with a fluency account in which subjects may have misattributed the ease of understanding or imagining the commodity as a sign that the claim was true (Jacoby, Woloshyn, \& Kelley, 1989; Schwarz, 2010). Indeed, we know that other manipulations that add context information, such as words that help describe a target, can lead people to conclude that an associated claim is true. For instance, a claim about Nick Cave seems more true when his name is accompanied by words such as "white male, musician, microphone"- perhaps because the words (although nonprobative) help people understand who he is, and this produces a feeling of conceptual fluency (Newman et al., 2012; Whittlesea, 1993).

Although we found that nonprobative photos produced truthiness for the future, there are at least two reasons to expect that photos would not influence judgments about a more immediate future. First, events that are closer in time are more detailed and concrete, and thus easier for people to bring to mind and imagine (Alter \& Oppenheimer, 2008; Hansen \& Wänke, 2010; Trope \& Liberman, 2003, 2010). Perhaps when claims are close in time an accompanying photo would not add anything because people would find the claim easy to

\footnotetext{
${ }^{1}$ We had 68 responses to this follow-up question.
}

imagine and comprehend (Schwarz, 2010; Sherman et al., 1985; Unkelbach, 2007). Second, in the context of the commodity market, people may have an implicit belief that prices do not vary within a matter of weeks. If so, then we might predict that photos would not influence people's beliefs about claims concerning near future relative to distant future events.

\section{Experiment 2}

\section{Method}

Subjects In Experiment 2, we used the Amazon Mechanical Turk (MTurk; www.mturk.com) to recruit 200 subjects. $^{2}$ Because of a quirk in the way MTurk assigns subject slots, 184 subjects completed the experiment (similar deviations follow in the other experiments we report here). These people received a \$0.60 Amazon credit.

Design We used a 2 (Photo: yes, no) $\times 2$ (Temporal distance: near, far $) \times 2$ (Claim; increase, decrease) mixed design, manipulating the presence of a photo within subjects.

Procedure We used the same method and materials as in Experiment 1B, except that we altered the claims so that our subjects responded to a claim set in the near or the distant future. People either responded to the distant claim that "This commodity is likely to have increased [decreased] in price three months from today" or a temporally close claim that "This commodity is likely to have increased [decreased] in price three weeks from today." This time manipulation is within the range commonly used in the mental-construal literature (for reviews, see Trope \& Liberman, 2003, 2010). We counterbalanced so that people responded to the three months/ three weeks and increase/decrease claims equally often, and each commodity equally often appeared with and without a photo.

\footnotetext{
${ }^{2}$ We determined the $N$ on the basis of previous research with photos and past judgments on Mturk (e.g., Newman et al., 2015).
} 

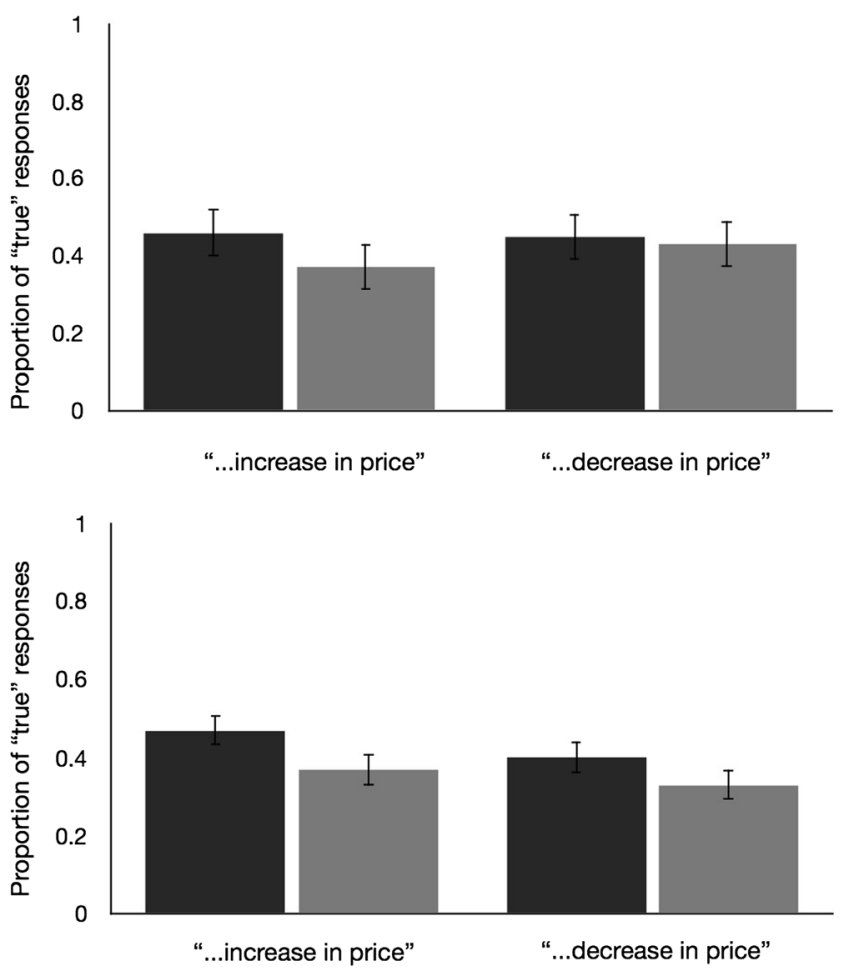

Fig. 2 Experiments 1A (top) and 1B (bottom): Proportions of "true" responses for claims that commodities would increase or decrease in price, presented with or without photos. Error bars represent $95 \%$ within-subjects confidence intervals.

\section{Results and discussion}

As Fig. 3 shows, photos produced truthiness for both near and far future claims, $F(1,180)=13.88, p<.01$, mean difference $=$ $.04,95 \%$ CI $[.02, .07]$. Moreover, people thought claims about the far future were more likely to be true than near future claims; indeed, people tended to disbelieve claims set in the near future (the bars on the left side of the graph all fall below $50 \%$ ), a finding that fits with the idea that people expect less

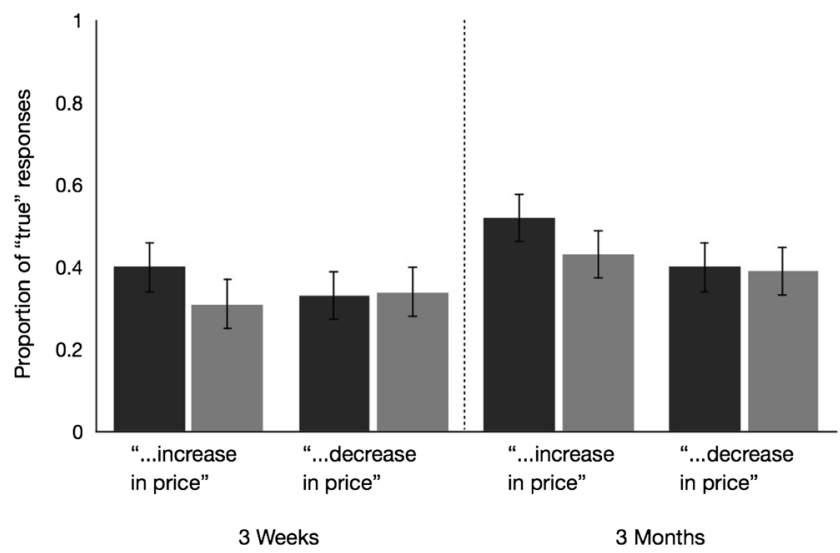

Fig. 3 Experiment 2: Proportions of "true" responses for claims that commodities would increase or decrease in price in three weeks or three months, presented with or without photos. Error bars represent $95 \%$ within-subjects confidence intervals. fluctuation over short intervals, $F(1,180)=12.99, p<.01$, mean difference $=-.09,95 \%$ CI $[-.14,-.04$,$] . As in the$ marginal tendency observed in Experiment $1 \mathrm{~B}$, we found that people agreed more with the increase than with the "decrease" claim, $F(1,180)=5.08, p=.03$, mean difference $=.06,95 \%$ CI $[.01, .11]$. Finally, the pattern in which the photos exerted a directionally stronger influence on the "increase" claim in Experiment $1 \mathrm{~A}$ emerged as a significant interaction in this experiment: We found significant truthiness for the "increase" claim, $F(1,180)=15.03, p<.01$, mean difference Incr $_{\text {In }}=.08$, $95 \%$ CI $[.05, .11]$, but not for the "decrease" claim, mean difference $_{\text {Decr }}=.002,95 \%$ CI $[-.03, .03]$.

Taken together, these data suggest that nonprobative photos can promote the truthiness of claims about a future price increase, even when people judge claims about the more immediate future and when people have a low belief in the claims they are judging (Fig. 3 shows that people in the three-weeks condition had lower belief in all of the claims). Put another way, photos can also shift people's belief in claims they tend to think are false.

The finding that photos encouraged more truthiness for the "increase" claim fits with two lines of research. First, it fits with research showing that people tend to see the future through "rose-colored" lenses: That is, they generate positive future scenarios more quickly and remember imagined positive future scenarios better than negative ones (Newby-Clark \& Ross, 2003; Szpunar, Addis, \& Schacter, 2012). Second, it fits with research showing that people often interpret an experience of easy processing in a positive way - and so, a feeling of fluency increases judgments of liking but not of disliking and boosts evaluations of beauty but not of ugliness (Reber, Schwarz, \& Winkielman, 2004; Winkielman, Schwarz, Reber, \& Fazendeiro, 2003; see also Harmon-Jones \& Allen, 2001, and cf. Westerman, Lanska, \& Olds, 2015). These fluent experiences are sometimes accompanied by physiological markers of positive affect (Reber, Winkielman, \& Schwarz, 1998; Seamon, McKenna, \& Binder, 1998; Topolinski, Likowski, Weyers, \& Strack, 2008; Winkielman \& Cacioppo, 2001).

These ideas suggest that photos of commodities may have given rise to a positive experience of processing fluency that in turn enhanced people's tendency to view the future as rosy. It may be that subjects made their judgments from the perspective of a buyer, rather than a seller, and hence tended to evaluate future price increases as positive. This explanation could account for the tendency in Experiment $1 \mathrm{~B}$ and both conditions of Experiment 2 for the effect of photos to be larger for "increase" than for "decrease" judgments. In Experiments $3 \mathrm{~A}$ and $\mathrm{B}$, we examined this positivity explanation more directly. In Experiment $3 \mathrm{~A}$, we simply asked people whether they thought the "increase" and "decrease" claims felt positive or negative. In Experiment 3B, we took a different approach and altered the claims so that the interpretation of the 
"increase" or "decrease" claims was clearly positive (making a profit) or negative (making a loss) for the subject. If we found that photos influence judgments for "profit" but not for "loss" claims, this would be better evidence that the influence of photos was tied to positive/rosy future claims.

\section{Experiment 3A}

\section{Method}

Subjects Again, we used MTurk to recruit 253 subjects. ${ }^{3}$ Each subject received $\$ 0.10$ Amazon credit for participating in this shorter experiment.

Design We used a one-way between-subjects design (Claim: increase, decrease).

Procedure The procedure was similar to that of Experiment 1B-subjects saw the "increase" or the "decrease" claim, and then made judgments about whether that claim was true or false for each commodity that appeared on the screen-except that subjects only evaluated ten commodities, selected at random from the full set of 68 . The commodities task served to give subjects a flavor of the judgment task. After subjects had completed the ten true/false judgments, they were asked to rate the affective valence of the claim they had just judged from $1=$ negative to $6=$ positive.

\section{Results and discussion}

We classified people's responses according to whether they responded to the "increase" or "decrease" claim. We found that subjects rated the "increase" claim as more positive $(M=$ $4.56,95 \%$ CI $[4.36,4.76])$ than the "decrease" claim $(M=$ $3.39,95 \%$ CI $[3.18,3.59]), t(250)=7.99, p<.001$, mean difference $=1.17,95 \% \mathrm{CI}$ of the difference $[0.89,1.46]$, a pattern consistent with the idea that photos promote truth for rosy future claims.

\section{Experiment 3B}

\section{Method}

Subjects We used MTurk to recruit 220 subjects. Each subjects received \$0.60 Amazon credit for participating.

\footnotetext{
$\overline{{ }^{3} \text { We posted } 200}$ subject slots, but because they were in multiple batches, more subjects participated than anticipated.
}

Design We used a 2 (Photo: yes, no) $\times 2$ (Relevance: selfrelevant, not self-relevant) $\times 2$ (Price: up, down) mixed design, manipulating the presence of a photo within subjects.

Procedure We used the same method and materials as in Experiment 2, except that we altered the claims so that half the subjects evaluated a claim that was personally relevant. That is, people either responded to the standard claim, "This commodity is likely to have increased [decreased] in price three months from today" or to a self-relevant claim, "If I buy this commodity today, then three months from now I will have made a profit [loss]." We counterbalanced so that people responded to the profit/loss and increase/decrease claims equally often, and each commodity appeared equally often with and without a photo.

\section{Results and discussion}

As Fig. 4 shows, we replicated the finding that photos significantly promoted truthiness for positive but not for negative claims. We also found that this pattern held for self-relevant claims, which is a stronger test of our positivity hypothesis. Although people responded "true" equally often to the "decrease" and "loss" claims, they responded "true" more to the "increase" than to the "profit" claim. That is, we observed a Photo $\times$ Price interaction, $F(1,216)=51.10, p<.01$ (photo vs. no photo: mean difference ${ }_{\text {Pos }}=.11,95 \%$ CI [.08, .13]; mean difference $\left.\mathrm{Neg}_{\mathrm{N}}=-.03,95 \% \mathrm{CI}[-.06,-.01]\right)$, and a significant Relevance $\times$ Price interaction, $F(1,216)=7.47, p=$ .01 (truth ratings for self-relevant vs. not self-relevant: mean difference $_{\mathrm{Pos}}=-.08,95 \% \mathrm{CI}[-.13,-.02]$; mean difference ${ }_{\mathrm{Neg}}$ $=.04,95 \% \mathrm{CI}[-.03, .10])$. We found no other interactions, all $F$ S $<1$.

The data from Experiments $3 \mathrm{~A}$ and $3 \mathrm{~B}$ support the idea that nonprobative photos promote rosiness. And Experiment $3 \mathrm{~B}$ shows that photos increased the truth of positive (but not of negative) future outcomes. This may be due to a mechanism whereby photos facilitate people's bias to think of positive future events, but these data also fit with a general effect in the fluency literature, in which fluency tends to increase judgments about positive but not about negative attributes (e.g., Reber et al., 2004; Winkielman et al., 2003). So it is possible that photos make positive future claims seem true because of the general tendency to experience fluency as positive, rather than because of a rose-colored bias in future thinking. If it is the case that photos enhance positive claims about the future largely because people interpret fluency in a positive way, then we should see a similar pattern for claims about the past. To address this hypothesis, in Experiment 4 we asked people to make judgments about both the future and the past. 


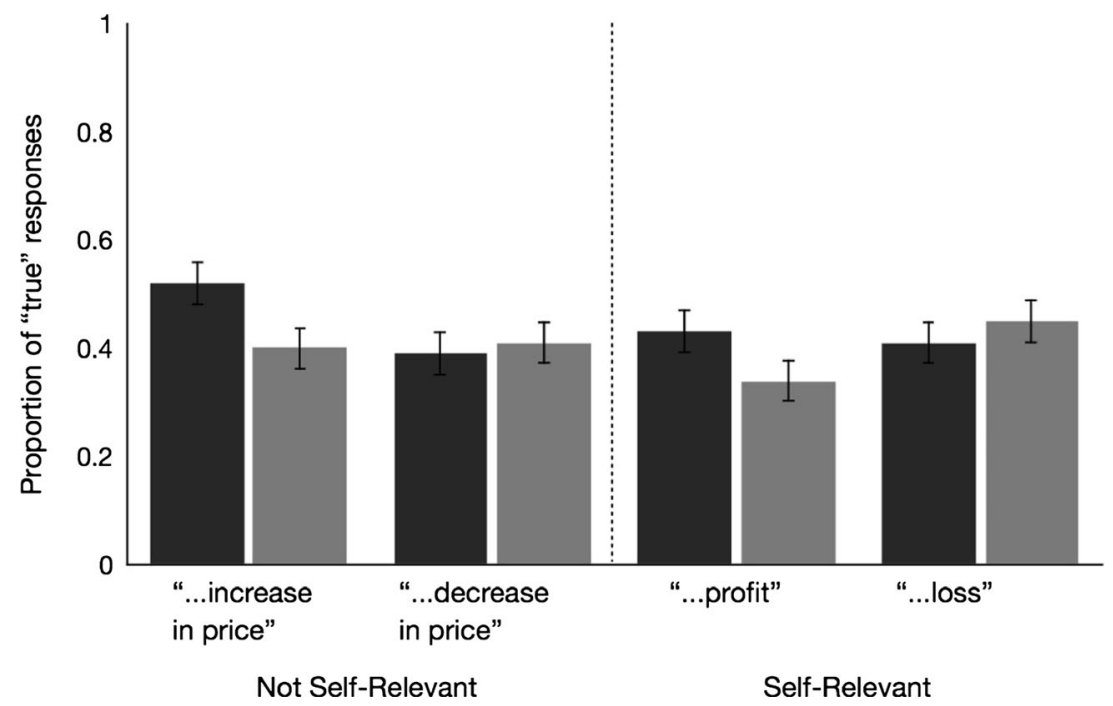

Fig. 4 Experiment 3B: Proportions of "true" responses for positive and negative claims about commodities that were either self-relevant or not selfrelevant, presented with or without photos. Error bars represent $95 \%$ within-subjects confidence intervals.

\section{Experiments 4A and 4B}

\section{Method}

Subjects We used MTurk to recruit 218 subjects. Each subject received $\$ 0.60$ Amazon credit for participating.

Design We used a 2 (Photo: yes, no) $\times 2$ (Time: past, future) $\times$ 2 (Price: worth more, worth less) mixed design, manipulating the presence of a photo within subjects.

Procedure We used the same method and materials as in Experiment 2, except that we altered the claims slightly so that subjects either responded to claims about the future (e.g., "Three months from now this commodity will be worth more [less] than it is today") or about the past (e.g., "Three months ago this commodity was worth more [less] than it is today"). We counterbalanced so that people responded to the past/future and "worth more"/"worth less" claims equally often, and each commodity appeared equally often with and without a photo.

\section{Results and discussion}

As Fig. 5 shows, we replicated the finding that for claims about the future, nonprobative photos promoted rosiness. But for claims about the past, truthiness was unrelated to valence: That is, photos promoted the truthiness for both positive and negative claims.

We observed a Photo $\times$ Time $\times$ Price interaction, $F(1,214)$ $=5.66, p=.02$ (future claims: mean difference More $=.08,95 \%$ CI $[.03, .12]$, mean difference Less $=.01,95 \%$ CI $[-.03, .05]$; past claims: mean difference ${ }_{\text {More }}=.06,95 \%$ CI $[.02, .10]$, mean difference Less $=.09,95 \%$ CI $[.05, .13])$. We found no other interactions, all $F_{\mathrm{s}}<1$. Considered together, these data suggest that something is indeed special about future claimsthat photos produce rosiness for judgments about the future, but general truthiness for claims about the past.

Because this pattern with the past claims was novel and different from our findings in Experiments 1-3, we replicated Experiment $4 \mathrm{~A}$. We used the same materials and increased our MTurk sample size by a factor of 3. In Experiment 4B, we found the same pattern of results - including, most notably, the key Photo $\times$ Time $\times$ Price interaction, $F(1,668)=8.34, p<$ .01 (future claims: mean difference ${ }_{\text {More }}=.11,95 \%$ CI [.08, $.13]$, mean difference Less $=.01,95 \%$ CI $[-.03, .04]$; past claims: mean difference More $=.07,95 \%$ CI $[.05, .09]$, mean difference $_{\text {Less }}=.04,95 \%$ CI $\left.[.02, .07]\right)$.

We then used the data from Experiments $4 \mathrm{~A}$ and $4 \mathrm{~B}$ to arrive at a more precise estimate of the truthiness effect sizes for both the "worth more" and "worth less" claims when set in the future or the past. We conducted two random-effects

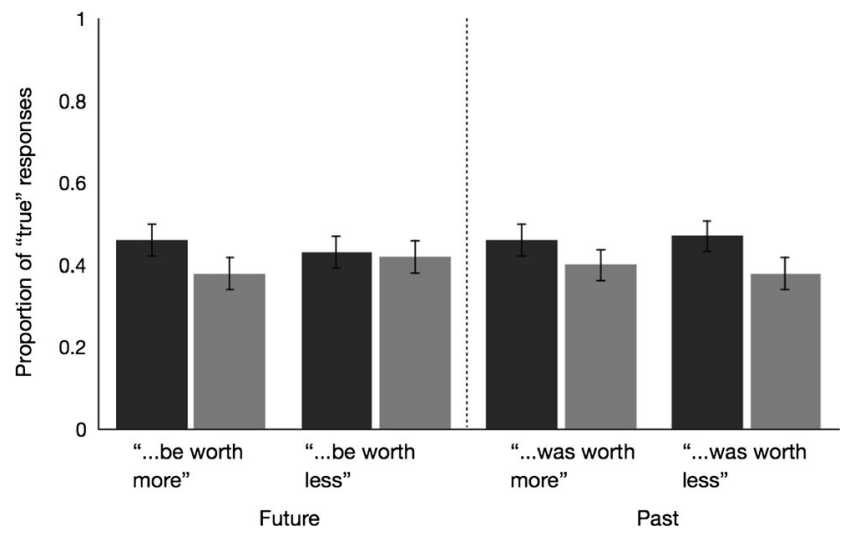

Fig. 5 Experiment 4A: Proportions of "true" responses for positive and negative commodity claims set in the future or the past, presented with or without photos. Error bars represent $95 \%$ within-subjects confidence intervals. 
model mini-meta-analyses (Cumming, 2012), and display those data in Fig. 6. The top part of the figure shows the first analysis, which focused on the "worth more" claims. We compared the effects for future and past truthiness, and calculated estimated raw effect sizes of $0.10,95 \%$ CI $[0.08,0.12]$, for the future and 0.07, $95 \%$ CI [0.05, 0.09], for the past. As Fig. 6 shows, the truthiness for the future was trivially larger: estimated raw difference $-0.03,95 \%$ CI $[-0.06,-0.005]$.

The bottom part of the figure shows the second analysis, which focused on the "worth less" claim. We again compared the truthiness effect sizes for future and past claims, and calculated estimated raw effect sizes of $0.01,95 \%$ CI $[-0.03$, 0.05], for the future, and $0.06,95 \% \mathrm{CI}[0.03,0.10]$, for the past. As Fig. 6 shows, the estimated raw effect sizes for future truthiness plausibly include the possibility that photos do not promote truthiness, whereas the estimate for the past condition does not. In addition, the overall difference between the sizes of the photo effects across the future and past conditions shows that there is plausibly no difference, $0.05,95 \% \mathrm{CI}[-$ $0.01,0.10]$.

\section{General discussion}

Photos, like memory, are a record of the past. But just as recent work has shown that we draw on the past to imagine the future (Addis, Wong, \& Schacter, 2007; Suddendorf \& Corballis, 2007; Szpunar, 2010; Szpunar, Watson, \& McDermott, 2007; cf. Johnson \& Sherman, 1990), we found that people drew on photos to predict the future. Across seven experiments, our data tell a consistent story: Photos promoted rosiness for future events. This finding fits with a growing body of work showing that people tend to see future events through rose-colored lenses (Sharot, Riccardi, Raio, \& Phelps, 2007; Szpunar et al., 2012; Taylor \& Brown, 1988; Weinstein, 1980; cf. Szpunar \& Schacter, 2013). If people are biased to anticipate positive future outcomes, it makes sense that they would use photos as hypothesis-confirming evidence for positive but not for negative claims (see the confirmation bias; e.g., Nickerson, 1998). Indeed, in each experiment, the confidence intervals of the effect sizes for the negative future claims included zero as a plausible value (with the exception of Exp. $3 \mathrm{~B}$, in which a negative or close-to-zero effect was plausible).

Although our results are consistent with the literature on cognitive fluency, mental construal, and the sourcemonitoring framework (Alter \& Oppenheimer, 2009; Hansen \& Wänke, 2010; Johnson et al., 1993; Lindsay, 2008), there are alternative explanations for our findings. One possibility is that photos did not boost fluency nor foster the ability to imagine a claim, but that subjects used a rule in which they assumed that photos lent credibility to the claims. But our results do not square with this account: If people suspected that photos lent credibility to a claim, we should have seen truthiness for both the "increase" and "decrease" claims. We did not see that pattern; photos had the most pronounced effect on positive claims, and a negligible effect on negative claims. Only when we asked people to make judgments about the past did photos produce truthiness for both types of claims. Moreover, when we asked people at the end of Experiment 1A about how the photos may have influenced their answers, the large majority of our subjects reported that the photo helped them understand what each commodity was - a finding that is consistent with the idea that photos made it easier for people to imagine the claim at hand.

A second alternative account of our effects is the possibility that the photos somehow made the commodities seem more valuable. Such a mechanism might explain why we saw an increase in perceived truth for the positive and not for the negative claims. There are several reasons why we do not think the value mechanism can explain our findings. First, our photos simply depicted the commodity on its own, without packaging or advertising (e.g., a hunk of raw manganese), and thus should not have conveyed information about its value. Second, if photos were a cue to value, we should have seen

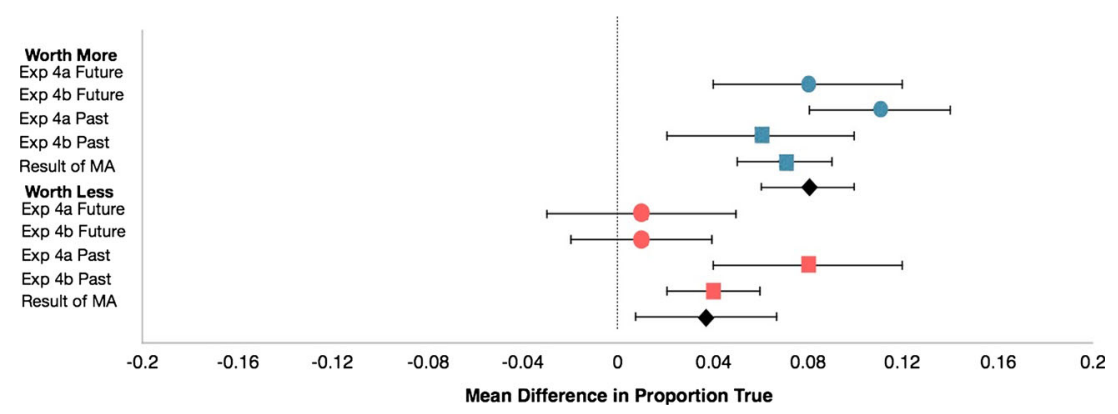

Fig. 6 Forest plot of the photo effect sizes between conditions and across experiments (Derzon \& Alford, 2013). The top panel of the plot displays the effects for photos in the "worth more" condition. The bottom panel of the plot displays the effects for photos in the "worth less" condition. The location of each shape on the horizontal axis represents the raw effect size - the difference between people's "true" responses when they saw claims paired with a photo versus when they saw claims without photos.
The lines extending on either side of a shape represent $95 \%$ confidence intervals (CIs; note that a $95 \%$ CI for a mean difference that excludes zero will be significantly different from zero using null hypothesis significance testing). Finally, within each panel on the plot, data that fall to the right of the zero line show that people were inclined to say "true" more often when they saw a photo- "rosiness" for future claims, and "truthiness" for past claims. 
that photos increased belief in the positive claims and decreased belief in the negative claims. That is, people should have taken the photos as evidence against claims that the commodity would decrease in price. Instead, we found that photos increased belief in positive claims and that they did very little to influence people's judgments about negative claims. Finally, we found that when people made judgments about the past, photos increased their belief in both positive and negative claims - a pattern that is also inconsistent with the idea that photos signal value.

Our data raise another intriguing question: Why is it that photos produced similar effects for both positive and negative past claims? We think there are at least two possibilities. First, we know that people think about the past in a flexible way. We recall events as being either better or worse than they really were, and we can come to remember both positive and negative events that never actually happened (Hyman \& Pentland, 1996; Loftus \& Pickrell, 1995; Ross \& Wilson, 2003; Schryer \& Ross, 2012; Wade et al., 2002). Second, that we detected truthiness for the past may be a consequence of the ways that the claims were worded. That is, it could be that the photos inflated "yes" responses to questions about both past increases and past decreases because subjects had difficulty interpreting the implications of past increases versus decreases.

A future increase in the price of a commodity represents a gain, and a future decrease in its price represents a loss, both of which seems naturally and intuitively positive or negative (higher price $=$ gain $=$ good; lower price $=$ loss $=$ bad). In contrast, if a commodity used to be worth less when you bought it than it is today, that represents a gain, but it seems less natural and intuitive (lower price $=$ gain $=$ good $)$. Likewise if it used to be worth more, that represents a loss (higher price $=$ loss $=$ bad). So, it is possible that the consequences of the past claims (whether you gained or lost money, whether the outcome was good or bad) were difficult to extract for subjects while they were making these quick judgments. If so, that might have made the "increase" and "decrease" judgments affectively comparable, and that, in turn, might have set the stage for the truthiness pattern in which photos inflate "yes" responses to both alternatives.

This pattern for past claims squares with an earlier finding in which photos inflated "true" responses to two alternative claims - either that "this famous person is alive" or that "this famous person is dead" (Newman et al., 2012). In both of these experiments, the apparent valence of the claim did not alter the effect of photos. In contrast, yet-to-be published data that are part of a thesis by Cardwell (2015), show that when valence is described in a concrete way, past claims look more like future claims. For instance, when people were asked to evaluate relatively concrete claims about the past, such as "this wine was rated [high] low in quality," photos produced truthiness for positive but not for negative claims (Cardwell, 2015). Further investigation of this intriguing pattern for past claims will be an interesting avenue for future research.

Might photos influence high-stakes, real-world judgments about financial investments? That is an empirical question, but there is evidence that important financial decisions can be sensitive to tangential factors such as ease of processing. For example, Alter and Oppenheimer (2006) showed that stock names and ticker labels that are easy to pronounce tended to perform better (especially in the short term) than those that are difficult to pronounce. So, even when real money is involved, surface-level features that logically should not bear on people's judgments sometimes do just that. These findings suggest to us that our photo-rosiness effect may indeed have realworld implications.

Across several experiments, nonprobative photos encouraged subjects to believe in positive claims about commodity fluctuations. One of the many questions these findings raise is whether we would see effects of rosiness for more autobiographical future claims. For instance, would seeing a photo of scuba diving lead people to predict they were more likely to go diving in the future? Another interesting possibility is that some people might show a reverse effect. If rosiness occurs because people are biased to view the future in a positive light, perhaps people who suffer from anxiety and depression would be swayed into believing negative, more than positive, future claims. These are just some of the future research avenues that will stem from our findings. We encourage researchers to explore this new effect and its implications in the domain of future thinking.

Author note E.J.N. is now at the Mind and Society Center, University of Southern California, and T.A. is now in the Department of Psychological Sciences, Kent State University. This research was supported by the New Zealand Government through the Marsden Fund, administered by the Royal Society of New Zealand on behalf of the Marsden Fund Council, and by the Natural Sciences and Engineering Research Council of Canada.

\section{References}

Addis, D. R., Wong, A. T., \& Schacter, D. L. (2007). Remembering the past and imagining the future: Common and distinct neural substrates during event construction and elaboration. Neuropsychologia, 45, 1363-1377. doi:10.1016/j. neuropsychologia.2006.10.016

Alter, A. L., \& Oppenheimer, D. M. (2006). Predicting short-term stock fluctuations by using processing fluency. Proceedings of the National Academy of Sciences, 103, 9369-9372. doi:10.1073 /pnas.0601071103

Alter, A. L., \& Oppenheimer, D. M. (2008). Easy on the mind, easy on the wallet: The roles of familiarity and processing fluency in valuation judgments. Psychonomic Bulletin \& Review, 15, 985-990. doi:10.3758/PBR.15.5.985

Alter, A. L., \& Oppenheimer, D. M. (2009). Suppressing secrecy through metacognitive ease: Cognitive fluency encourages self-disclosure. 
Psychological Science, 20, 1414-1420. doi:10.1111/j.14679280.2009.02461.x

Blandón-Gitlin, I., Pezdek, K., Lindsay, D. S., \& Hagen, L. (2009). Criteria-based content analysis of true and suggested accounts of events. Applied Cognitive Psychology, 23, 901-917. doi:10.1002 /acp.1504

Cardwell, B. A. (2015). Non-probative photos promote the truth of positive claims (Unpublished $\mathrm{PhD}$ thesis). Victoria University of Wellington, New Zealand.

Cumming, G. (2012). Understanding the new statistics: Effect sizes, confidence intervals, and meta-analysis. New York, NY: Routledge.

Derzon, J. H., \& Alford, A. A. (2013). Forest plots in Excel: moving beyond a clump of trees to a forest of visual information. Practical Assessment, Research \& Evaluation, 18(7), 2.

Fenn, E., Newman, E. J., Pezdek, K., \& Garry, M. (2013). The effect of nonprobative photographs on truthiness persists over time. Acta Psychologica, 144, 207-211. doi:10.1016/j.actpsy.2013.06.004

Hansen, J., \& Wänke, M. (2010). Truth from language and truth from fit: The impact of linguistic concreteness and level of construal on subjective truth. Personality and Social Psychology Bulletin, 36, 15761588. doi: $10.1177 / 0146167210386238$

Harmon-Jones, E., \& Allen, J. J. B. (2001). The role of affect in the mere exposure effect: Evidence from psychophysiological and individual differences approaches. Personality and Social Psychology Bulletin, 27, 889-898.

Hyman, I. E., Jr., \& Pentland, J. (1996). The role of mental imagery in the creation of false childhood memories. Journal of Memory and Language, 35, 101-117.

Jacoby, L. L., Kelley, C. M., \& Dywan, J. (1989). Memory attributions. In H. L. Roediger III \& F. I. M. Craik (Eds.), Varieties of memory and consciousness: Essays in honour of Endel Tulving (pp. 391-422). Hillsdale, NJ: Erlbaum.

Jacoby, L. L., Woloshyn, V., \& Kelley, C. (1989). Becoming famous without being recognized: Unconscious influences of memory produced by dividing attention. Journal of Experimental Psychology: General, 118, 115-125. doi:10.1037/0096-3445.118.2.115

Johnson, M. K., Hashtroudi, S., \& Lindsay, D. S. (1993). Source monitoring. Psychological Bulletin, 114, 3-28. doi:10.1037/00332909.114.1.3

Johnson, M. K., \& Sherman, S. J. (1990). Constructing and reconstructing the past and the future in the present. In T. Higgins \& R. Sorrentino (Eds.), Handbook of motivation and cognition: Foundations of social behavior (Vol. 2, pp. 482-526). New York, NY, US: Guilford Press.

Lindsay, D. S. (2008). Source monitoring. In J. H. Byrne (Ed. in Chief) \& H. L. Roediger III (Vol. Ed.), Learning and memory: A comprehensive reference: Vol. 2. Cognitive psychology of memory (pp. 325348). Amsterdam, The Netherlands: Elsevier.

Lindsay, D. S. (2014). Memory source monitoring applied. In T. Perfect \& D. S. Lindsay (Eds.), Sage handbook of applied memory (pp. 59 75). London, UK: Sage.

Lindsay, D. S., Hagen, L., Read, J. D., Wade, K. A., \& Garry, M. (2004). True photographs and false memories. Psychological Science, 15, 149-154. doi:10.1111/j.0956-7976.2004.01503002.x

Loftus, E. F., \& Pickrell, J. (1995). The formation of false memories. Psychiatric Annals, 25, 720-724.

Newby-Clark, I., \& Ross, M. (2003). Conceiving the past and future. Personality and Social Psychology Bulletin, 29, 807-818. doi:10.1177/0146167203253120

Newman, E. J., Garry, M., Bernstein, D. M., Kantner, J., \& Lindsay, D. S. (2012). Nonprobative photographs (or words) inflate truthiness. Psychonomic Bulletin \& Review, 19, 969-974. doi:10.3758 /s13423-012-0292-0

Newman, E. J., Garry, M., Unkelbach, C., Bernstein, D. M., Lindsay, D. S., \& Nash, R. A. (2015). Truthiness and falsiness of trivia claims depend on judgmental contexts. Journal of Experimental
Psychology: Learning, Memory, and Cognition, 41, 1337-1348. doi:10.1037/xlm0000099

Nickerson, R. S. (1998). Confirmation bias: A ubiquitous phenomenon in many guises. Review of General Psychology, 2, 175-220. doi:10.1037/1089-2680.2.2.175

Petrova, P. K., \& Cialdini, R. B. (2005). Fluency of consumption imagery and the backfire effects of imagery appeals. Journal of Consumer Research, 32, 442-452. doi:10.1086/497556

Reber, R., Schwarz, N., \& Winkielman, P. (2004). Processing fluency and aesthetic pleasure: Is beauty in the perceiver's processing experience? Personality and Social Psychology Review, 8, 364-382. doi:10.1207/s15327957pspr0804_3

Reber, R., Winkielman, P., \& Schwarz, N. (1998). Effects of perceptual fluency on affective judgments. Psychological Science, 9, 45-48. doi:10.1111/1467-9280.00008

Ross, M., \& Wilson, A. E. (2003). Autobiographical memory and conceptions of self getting better all the time. Current Directions in Psychological Science, 12, 66-69. doi:10.1111/1467-8721.01228

Schacter, D. L., Addis, D. R., \& Buckner, R. L. (2007). Remembering the past to imagine the future: the prospective brain. Nature Reviews Neuroscience, 8, 657-661.

Schryer, E., \& Ross, M. (2012). People's thoughts about their personal past and futures. In P. Briñol \& K. G. DeMarree (Eds.), Social metacognition (pp. 141-158). New York, NY: Psychology Press.

Schwarz, N. (2010). Meaning in context: Metacognitive experiences. In B. Mesquita, L. F. Barrett, \& E. R. Smith (Eds.), The mind in context (pp. 105-125). New York, NY: Guilford.

Seamon, J. G., McKenna, P. A., \& Binder, N. (1998). The mere exposure effect is differentially sensitive to different judgment tasks. Consciousness and Cognition, 7, 85-102.

Sharot, T., Riccardi, A. M., Raio, C. M., \& Phelps, E. A. (2007). Neural mechanisms mediating optimism bias. Nature, 450, 102-105. doi:10.1038/nature06280

Sherman, S. J., Cialdini, R. B., Schwartzman, D. F., \& Reynolds, K. D. (1985). Imagining can heighten or lower the perceived likelihood of contracting a disease: The mediating effect of ease of imagery. Personality and Social Psychology Bulletin, 11, 118-127. doi:10.1177/0146167285111011

Suddendorf, T., \& Corballis, M. C. (2007). The evolution of foresight: What is mental time travel, and is it unique to humans? Behavioral and Brain Sciences, 30, 299-313.

Szpunar, K. K. (2010). Episodic future thought an emerging concept. Perspectives on Psychological Science, 5(2), 142-162.

Szpunar, K. K., Addis, D. R., \& Schacter, D. L. (2012). Memory for emotional simulations: Remembering a rosy future. Psychological Science, 23, 24-29. doi:10.1177/0956797611422237

Szpunar, K. K., \& Schacter, D. L. (2013). Get real: Effects of repeated simulation and emotion on the perceived plausibility of future experiences. Journal of Experimental Psychology: General, 142, 323327. doi:10.1037/a0028877

Szpunar, K. K., Watson, J. M., \& McDermott, K. B. (2007). Neural substrates of envisioning the future. Proceedings of the National Academy of Sciences, 104, 642-647. doi:10.1073/pnas.0610082104

Taylor, S. E., \& Brown, J. D. (1988). Illusion and well-being: A social psychological perspective on mental health. Psychological Bulletin, 103, 193-210. doi:10.1037/0033-2909.103.2.193

Topolinski, S., Likowski, K. U., Weyers, P., \& Strack, F. (2008; 2009). The face of fluency: Semantic coherence automatically elicits a specific pattern of facial muscle reactions. Cognition and Emotion, 23, 260-271. doi:10.1080/02699930801994112

Trope, Y., \& Liberman, N. (2003). Temporal construal. Psychological Review, 110, 403-421. doi:10.1037/0033-295X.110.3.403

Trope, Y., \& Liberman, N. (2010). Construal-level theory of psychological distance. Psychological Review, 117, 440-463. doi:10.1037 /a0018963 
Tversky, A., \& Kahneman, D. (1974). Judgment under uncertainty: Heuristics and biases. Science, 185, 1124-1131. doi:10.1126 /science.185.4157.1124

Unkelbach, C. (2006). The learned interpretation of cognitive fluency. Psychological Science, 17, 339-345.

Unkelbach, C. (2007). Reversing the truth effect: Learning the interpretation of processing fluency in judgments of truth. Journal of Experimental Psychology: Learning, Memory, and Cognition, 33, 219-230. doi:10.1037/0278-7393.33.1.219

Wade, K. A., Garry, M., Read, J. D., \& Lindsay, D. S. (2002). A picture is worth a thousand lies: Using false photographs to create false childhood memories. Psychonomic Bulletin \& Review, 9, 597-603.

Weinstein, N. D. (1980). Unrealistic optimism about future life events. Journal of Personality and Social Psychology, 39, 806-820. doi:10.1037/0022-3514.39.5.806
Westerman, D. L., Lanska, M., \& Olds, J. M. (2015). The effect of processing fluency on impressions of familiarity and liking. Journal of Experimental Psychology: Learning, Memory, and Cognition, 41, 426-438. doi:10.1037/a0038356

Whittlesea, B. W. A. (1993). Illusions of familiarity. Journal of Experimental Psychology: Learning, Memory, and Cognition, 19, 1235-1253. doi:10.1037/0278-7393.19.6.1235

Winkielman, P., \& Cacioppo, J. T. (2001). Mind at ease puts a smile on the face: Psychophysiological evidence that processing facilitation elicits positive affect. Journal of Personality and Social Psychology, 81, 989-1000. doi:10.1037/0022-3514.81.6.989

Winkielman, P., Schwarz, N., Reber, R., \& Fazendeiro, T. (2003). Cognitive and affective consequences of visual fluency: When seeing is easy on the mind. In R. Baatra \& L. Scott (Eds.), Persuasive imagery: A consumer response perspective (pp. 75-89). Mahwah, NJ: Erlbaum. 